\title{
Anti-AIDS agents 88. Anti-HIV conjugates of betulin and betulinic acid with AZT prepared via click chemistry
}

\author{
Ibrahim D. Boria ${ }^{a}$, Hsin-Yi Hunga ${ }^{a}$, Keduo Qiana, ${ }^{*}$, Chin-Ho Chen ${ }^{b}$, Susan L. Morris- \\ Natschke ${ }^{a}$, and Kuo-Hsiung Lee ${ }^{a, c,{ }^{*}}$ \\ aNatural Products Research Laboratories, UNC Eshelman School of Pharmacy, University of \\ North Carolina, Chapel Hill, NC 27599, USA \\ bDepartment of Surgery, Duke University Medical Center, Durham, NC 27710, USA \\ ${ }^{\circ}$ Chinese Medicine Research and Development Center, China Medical University and Hospital, \\ Taichung 401, Taiwan
}

\begin{abstract}
In the present study, a new strategy to link AZT with betulin/betulinic acid (BA) by click chemistry was designed and achieved. This conjugation via a triazole linkage offers a new direction for modification of anti-HIV triterpenes. Click chemistry provides an easy and productive way for linking two molecules, even when one of them is a large natural product. Among the newly synthesized conjugates, compounds $\mathbf{1 5}$ and $\mathbf{1 6}$ showed potent anti-HIV activity with $\mathrm{EC}_{50}$ values of 0.067 and $0.10 \mu \mathrm{M}$, respectively, which are comparable to that of $\mathrm{AZT}\left(\mathrm{EC}_{50}\right.$ : $0.10 \mu \mathrm{M})$ in the same assay.
\end{abstract}

\section{Keywords}

Betulin; Betulinic acid; AZT; Anti-HIV; Click chemistry

\begin{abstract}
Due to the expanded and improved HIV programs, the number of new global HIV infections declined $19 \%$ over the past decade. However, this progress is fragile and unevenly distributed. HIV incidence is still increasing in some countries and regions, and too many new infections are occurring, 2.6 million in 2009 alone, contributing to the current global incidence of 33.3 million. ${ }^{1}$ New infections continue to outpace the number of people placed on treatment, and the efficacy of the treatments is hampered by the emergence of drugresistant viral strains and severe drug-drug interactions. Therefore, novel potent antiretroviral agents with different targets and acceptable prices are still urgently needed.
\end{abstract}

Two lupine-type triterpenes betulin and betulinic acid (BA), which are readily available from the birch tree in large quantity, exhibit diverse pharmacological activities, including anti-HIV, anti-cancer, and anti-inflammatory activities. ${ }^{2}$ Among the BA/betulin derivatives, bevirimat $\left[3-O-\left(3^{\prime}, 3^{\prime}\right.\right.$-dimethylsuccinyl $)$ betulinic acid, 14] was found to exhibit remarkable anti-HIV-1 activity against primary and drug-resistant HIV-1 isolates, ${ }^{3,4}$ representing a

\footnotetext{
(C) 2012 Elsevier Ltd. All rights reserved.

*Corresponding authors. Tel.: +1 9199661394 (K.Q.), tel.: +1 919962 0066; fax: +1 9199663893 (K.-H.L.). kdqian@unc.edu (K. Qian), khlee@unc.edu (K.-H. Lee).

Publisher's Disclaimer: This is a PDF file of an unedited manuscript that has been accepted for publication. As a service to our customers we are providing this early version of the manuscript. The manuscript will undergo copyediting, typesetting, and review of the resulting proof before it is published in its final citable form. Please note that during the production process errors may be discovered which could affect the content, and all legal disclaimers that apply to the journal pertain.
} 
unique first in a class of anti-HIV compounds termed maturation inhibitors (MIs). ${ }^{4,5}$ Bevirimat has recently succeeded in Phase IIb clinical trials. ${ }^{6-9}$

In our prior study, AZT ( $3^{\prime}$-azido- $3^{\prime}$-deoxythymidine), a clinically used nucleoside reverse transcriptase inhibitor (NRTI), was conjugated with $3-O-\left(3^{\prime}, 3^{\prime}\right.$-dimethylsuccinyl)betulin at its $\mathrm{C}-28$ position using different linkers. The goal was to provide multi-target therapeutics in one molecule in order to reduce the risk of drug-drug interaction, which can occur from mixing monotherapies,. ${ }^{10}$ The conjugates were formed via an ester bond, which was meant to subsequently be hydrolyzed inside the cells and release two different chemical entities exerting two pharmacological functions, anti-maturation and anti-reverse transcriptase. However, one potential drawback of this design is that the hydroxyl group of AZT, which needs to undergo phosphorylation inside host cells to become active, forms the linker bond with the betulin derivatives. Consequently, the inhibitory ability of AZT is highly dependent on the ability of the conjugate to dissociate. In order to improve this issue, we investigated another strategy to link AZT with betulin and BA via the azido group of AZT by using click chemistry.

Click chemistry as introduced by K. Barry Sharpless is a chemical philosophy to mimic nature's ability to make carbon-heteroatom bonds rather than carbon-carbon bonds. ${ }^{11}$ Conjugation of AZT with betulin and BA by this methodology has the following potential benefits. 1) Click chemistry is designed to link the azido group of AZT with an alkyne group on betulin/BA derivatives, leaving the hydroxyl group of AZT free to be phosphorylated. 2) The linking triazole group is physiologically stable in cells. Thus, the new conjugated molecule will not be degraded inside the cells, which should reduce the potential drug-drug interactions. 3) In addition, the triazole linkage formed by click chemistry may also offer extra interaction with virus proteins. Based on this rationale, the present study reports the synthesis and anti-HIV activity of the newly designed AZT-betulin and AZT-BA conjugates.

The synthetic route to compounds conjugated at the C-3 position of betulin is outlined in Scheme 1 . The C-28 hydroxyl of betulin was first protected by reaction with tertbutyldimethylsilyl chloride (TBSCl) to yield the silyl ether 1. Prop-2-ynyl groups were then introduced at the C-3 position as either an ether (2) or carbonate ester (3). Compounds 2 and 3 were then reacted with the azido group of AZT in the presence of $\mathrm{Cu}$ and $\mathrm{CuSO}_{4} \cdot 5 \mathrm{H}_{2} \mathrm{O}$ to furnish final compounds $\mathbf{8}$ and $\mathbf{9}$ in quantitative yields. Analogous final compounds $\mathbf{1 0}$ and 11 were obtained by the same click reaction of AZT with the C-28 de-protected betulin derivatives 4 and $\mathbf{5}$. Oxidation of the C-28 hydroxyl of $\mathbf{4}$ with Jones reagent yielded $\mathbf{6}$, which was also reacted with AZT to yield 12, an AZT-BA conjugate. Finally, a $3^{\prime}, 3^{\prime}$ -

dimethylsuccinyl ester was introduced at the C-28 position of $\mathbf{4}$ to yield compound $\mathbf{7}$, which was converted by click chemistry to the conjugate 13. Scheme 2 depicts the synthesis of AZT-bevirimat conjugates. A prop-2-ynyl ester moiety was added to the C-28 position of bevirimat (14) to furnish 15, followed by click reaction of 15 with AZT to yield final compound 16. Compared with the previous yields (42.7-87.3\%) for conjugating AZT with betulin derivatives via an ester bond, ${ }^{10}$ the click reactions of AZT with betulin/BA derivatives were achieved quantitatively, which is a significant advantage in the last step of synthesizing the target compounds. In addition, the reaction time was shortened significantly to 30 min by using microwave conditions at $120^{\circ} \mathrm{C}$ (followed by dilution with EtOAc, washing with $\mathrm{NaHCO}_{3}$ and brine, and chromatography), rather than the prior overnight esterification reaction. Therefore, the click reaction provides a much more productive and rapid approach to obtain the final products of AZT-betulin/BA conjugates.

The anti-HIV activity data of all new compounds are summarized in Table 1 . Among the tested compounds, conjugates $\mathbf{8}$ and $\mathbf{1 3}$ with AZT linked through the C-3 side chain of 
betulin/BA showed moderate antiviral activity with $\mathrm{EC}_{50}$ values of 0.19 and $0.35 \mu \mathrm{M}$, respectively. The $\mathrm{C}-3$ ether bond $(\mathbf{8})$ was favored for activity compared with the C-3 carbonate ester bond (corresponding conjugate $\mathbf{9}$ was inactive). Conjugates with a free C-28 hydroxyl (10 and 11) or carboxylic acid group (12) showed no inhibitory activity, compared with conjugates with a C-28 TBS ether $(\mathbf{8})$ or dimethylsuccinyl ester (13). Between the two active conjugates, the smaller C-28 TBS side chain in $\mathbf{8}$ was favored compared with the longer dimethylsuccinyl side chain in 13. Overall, in this limited data set, when AZT and betulin/BA are conjugated at the C-3 position, a shorter distance between AZT-betulin/BA and the presence of a small extra side chain at C-28 are important for the conjugates' antiviral activity.

The non-conjugated 15 with a 3-O-3', $3^{\prime}$-dimethylsuccinyl side chain at C-3 and propynyl ester moiety at C-28 showed potent anti-HIV activity with an $\mathrm{EC}_{50}$ of $0.067 \mu \mathrm{M}$ and a selectivity index (SI, ratio of cytotoxic/anti-viral activity) of 226. The AZT-bevirimat conjugate $\mathbf{1 6}$ also exhibited anti-HIV activity with an $\mathrm{EC}_{50}$ of $0.10 \mu \mathrm{M}$ and a SI of 101. Thus, these two compounds and AZT $\left(\mathrm{EC}_{50}: 0.10 \mu \mathrm{M}\right)$ showed comparable activity in our assay system. As a pioneer compound, conjugate $\mathbf{1 6}$ demonstrates that a click reaction can be used easily with a large natural product (e.g. BA), which contains a terminal alkyne moiety, to form conjugates. The potent anti-HIV activity of compounds $\mathbf{1 5}$ and $\mathbf{1 6}$ proves that the incorporation of a C-28 side chain in bevirimat may result in retained or even increased antiviral activity. We are currently investigating synthesis and antiviral evaluation of additional AZT-bevirimat conjugates with different sizes/lengths of linkers between the C-28 carboxylic acid and the triazole moiety formed by click reaction with AZT.

In conclusion, conjugation via triazole linkage offers a new direction of modification of antiHIV triterpenes. Click chemistry provides an easy and productive way for linking two molecules, even when one of them is a large natural product. Preliminary results indicated that AZT-betulin/BA conjugates with proper substitutions at the C-3 and C-28 positions showed potent antiviral activity comparable to bevirimat and AZT. Mechanistic studies are currently ongoing.

\section{Acknowledgments}

This investigation was supported by Grant AI-077417 from the National Institute of Allergy and Infectious Diseases (NIAID) awarded to K.-H.L. This study was also supported in part by Taiwan Department of Health Clinical Trial and Research Center of Excellence (DOH100-TD-B-111-004). Efficient purification of all the synthetic BA analogs was performed with a Grace Reveleris ${ }^{\circledR}$ flash chromatography system equipped with RevealX(TM) detection allowing for multisignal (UV/ELSD) collection to low mg quantities. Reveleris ${ }$ Navigator method optimizer and Grace Reveleris ${ }^{\circledR}$ flash silica cartridges were employed for high quality separations.

\section{References}

1. HIV/AIDS strategy 2011. http://www.who.int/topics/hiv_aids/en/.

2. Alakurtti S, Makela T, Koskimies S, Yli-Kauhaluoma J. Eur J. Pharm. Sci. 2006; 29:1-13. [PubMed: 16716572]

3. Kashiwada Y, Hashimoto F, Cosentino LM, Chen CH, Garrett PE, Lee KH. J. Med. Chem. 1996; 39:1016-1017. [PubMed: 8676334]

4. Kanamoto T, Kashiwada Y, Kanbara K, Gotoh K, Yoshimori M, Goto T, Sano K, Nakashima H. Antimicrob. Agents Chemother. 2001; 45:1225-1230. [PubMed: 11257038]

5. Li F, Goila-Gaur R, Salzwedel K, Kilgore NR, Reddick M, Matallana C, Castillo A, Zoumplis D, Martin DE, Orenstein JM, Allaway GP, Freed EO, Wild CT. Proc. Natl. Acad. Sci. USA. 2003; 100:13555-13560. [PubMed: 14573704] 
6. Smith PF, Ogundele A, Forrest A, Wilton J, Salzwedel K, Doto J, Allaway GP, Martin DE. Antimicrob. Agents Chemother. 2007; 51:3574-3581. [PubMed: 17638699]

7. Martin DE, Blum R, Doto J, Galbraith H, Ballow C. Clin. Pharmacokinet. 2007; 46:589-598. [PubMed: 17596104]

8. Martin DE, Blum R, Wilton J, Doto J, Galbraith H, Burgess GL, Smith PC, Ballow C. Antimicrob. Agents Chemother. 2007; 51:3063-3066. [PubMed: 17576843]

9. Qian, K.; Nitz, TJ.; Yu, D.; Allaway, GP.; Morris-Natschke, SL.; Lee, KH. Natural Product Chemistry for Drug Discovery, for the Royal Society of Chemistry Biomolecular Sciences Series. Merlion Pharmaceuticals Pte Ltd Press; 2009. p. 374-391.

10. Xiong J, Kashiwada Y, Chen CH, Qian K, Morris-Natschke SL, Lee KH, Takaishi Y. Bioorg. Med. Chem. 2010; 18:6451-6646. [PubMed: 20673723]

11. Kolb HC, Finn MG, Sharpless KB. Angew. Chem. Int. Ed. 2001; 40:2004-2021.

12. Fioravanti S, Pellacani L, Tardella PA. Tetrahedron. 2009; 65:5747-5751.

13. Pradere U, Roy V, McBrayer TR, Schinazi RF, Agrofoglio LA. Tetrahedron. 2008; 64:9044-9051.

14. Delain-Bioton L, Villemin D, Lohier J-F, Sopkova J, Jaffrès P-A. Tetrahedron. 2007; 63:96779684. 

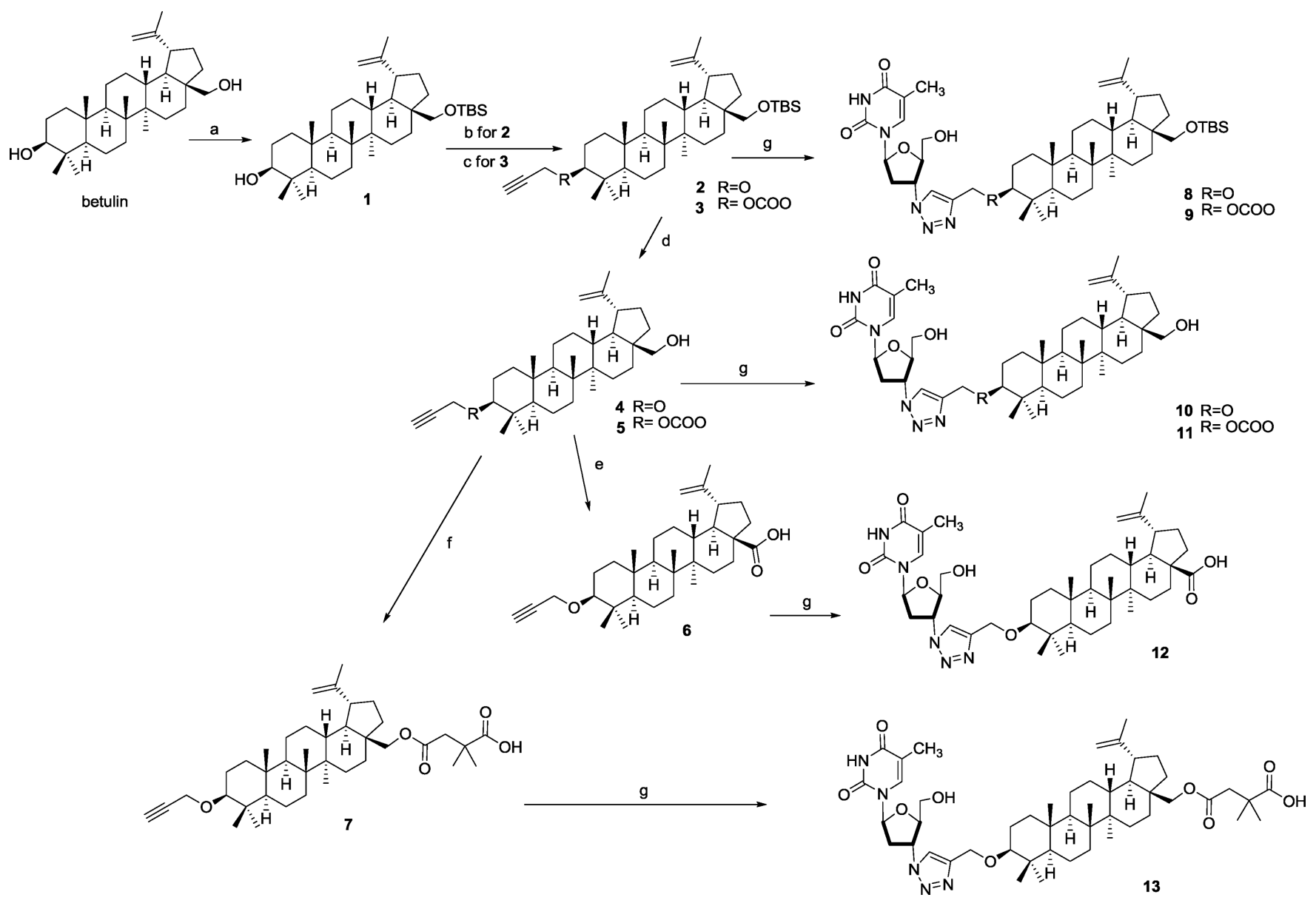

Scheme 1. AZT conjugation at $\mathrm{C}-3$ position

Reagents and conditions: (a) TBSCl, DMF/THF (1:1), DMAP, DIPEA, $0{ }^{\circ} \mathrm{C}$; (b) propargyl bromide, NaH, THF; (c) triphosgene, pyridine, THF, ${ }^{12}$ and then propargyl alcohol, pyridine, THF; (d) TBAF, THF; (e) Jones reagent, acetone; (f) 2,2-dimethylsuccinic anhydride,

DMAP, DMF, $70{ }^{\circ} \mathrm{C}$; (g) AZT, $\mathrm{Cu}, \mathrm{CuSO}_{4} \cdot 5 \mathrm{H}_{2} \mathrm{O}, \mathrm{H}_{2} \mathrm{O}, t$-BuOH, under $\mathrm{N}_{2} \cdot{ }^{13}, 14$ 


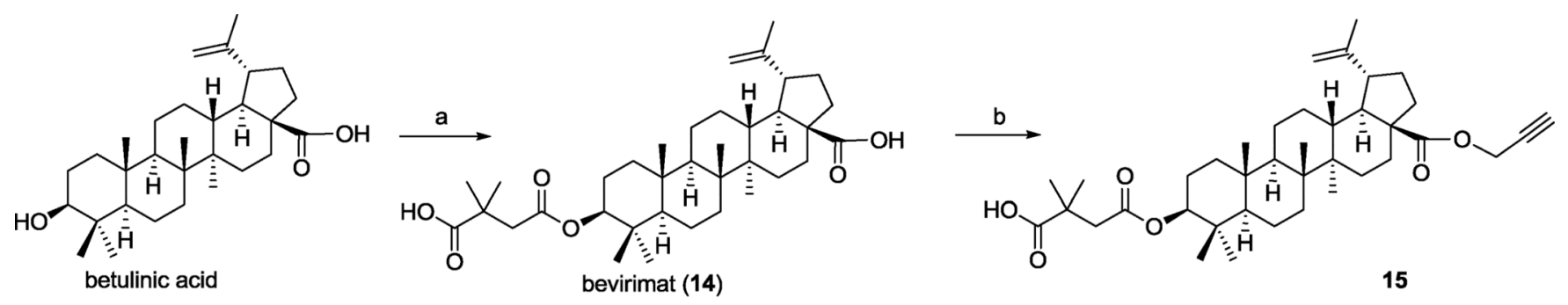
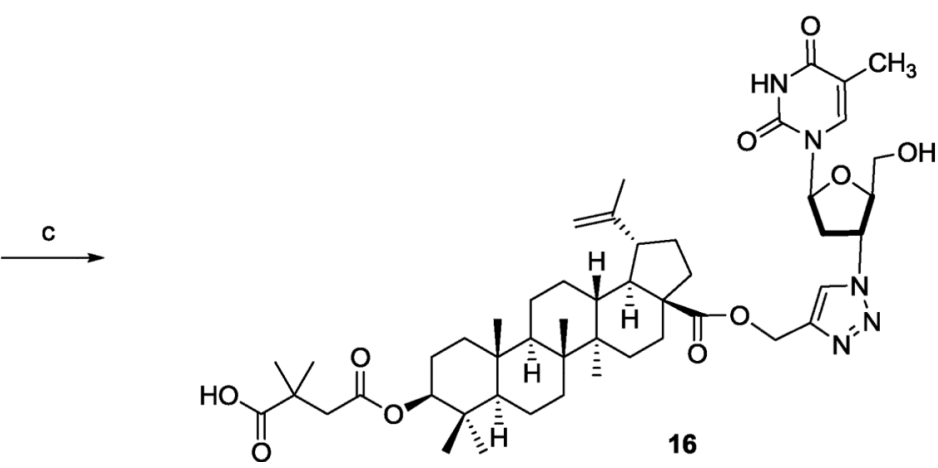

Scheme 2. AZT conjugation at C-28 position

Reagents and conditions: (a) 2,2-dimethyl-succinic anhydride, DMAP, DMF, $70{ }^{\circ} \mathrm{C}$; (b) propargyl bromide, $\mathrm{Cs}_{2} \mathrm{CO}_{3}$, DMF/THF (1:1), room temperature; (c) AZT, $\mathrm{Cu}$, $\mathrm{CuSO}_{2} \cdot 5 \mathrm{H}_{2} \mathrm{O}, \mathrm{H}_{2} \mathrm{O}, t-\mathrm{BuOH}$, under $\mathrm{N}_{2}$. 


\section{Table 1}

Anti-HIV data against HIV-1 ${ }_{\mathrm{NL} 4-3}$ infected MT-4 cells.

\begin{tabular}{cccc}
\hline Compound & $\mathbf{E C}_{\mathbf{5 0}}(\boldsymbol{\mu M})$ & $\mathbf{C C}_{\mathbf{5 0}}(\boldsymbol{\mu M})$ & $\mathbf{S I}^{\boldsymbol{a}}$ \\
\hline $\mathbf{2}$ & $-b$ & - & - \\
$\mathbf{3}$ & - & - & - \\
$\mathbf{4}$ & - & - & - \\
$\mathbf{5}$ & - & - & - \\
$\mathbf{6}$ & - & - & - \\
$\mathbf{7}$ & - & - & - \\
$\mathbf{8}$ & 0.19 & $>4.6$ & $>24$ \\
$\mathbf{9}$ & - & - & - \\
$\mathbf{1 0}$ & - & - & - \\
$\mathbf{1 1}$ & - & - & - \\
$\mathbf{1 2}$ & - & - & - \\
$\mathbf{1 3}$ & 0.35 & $>4.6$ & $>13$ \\
$\mathbf{1 5}$ & 0.067 & 15.3 & 226 \\
$\mathbf{1 6}$ & 0.10 & 11.2 & 101 \\
Bevirimat (14) & 0.077 & 13.2 & 171 \\
$\mathbf{A Z T}$ & 0.10 & 140 & 1385 \\
\hline
\end{tabular}

${ }^{a}$ Selectivity index $=\mathrm{CC}_{50} / \mathrm{EC}_{50}\left(\mathrm{CC}_{50}\right.$, the concentration of test sample that was cytotoxic to 50\% of the mock-infected cells; $\mathrm{EC}_{50}$, the concentration of the test sample that was effective to suppress HIV replication by $50 \%$ )

$b_{\text {No activity }}$ 